\title{
Diabetic Lower Extremity Ulcers and Hyperbaric Oxygen Therapy
}

\author{
Alexandra J. Bishop* \\ DDRC Healthcare, Plymouth, UK
}

Received: September 05, 2015; Accepted: September 25, 2015; Published: November 18, 2015

*Corresponding author: Alexandra J Bishop, DDRC Healthcare, Plymouth, UK, Tel: +0044 (0) 1752209999; Fax: +0044 (0) 1752209115; E-mail: bishopa@ddrc.org

\begin{abstract}
Diabetic wounds are a worldwide problem with significant effects for those whose wounds fail to heal as expected and who go on to require amputation. Standard care is generally effective in healing diabetic ulcers, but in some cases, adjunctive Hyperbaric Oxygen (HBO) may be beneficial.

Oxygen is essential throughout the wound healing processes including antimicrobial activity, growth factor production, angiogenesis and collagen synthesis. HBO has been shown to have a number of benefits to wound healing in diabetics, including reduction of infection, reduction of pathological inflammation and stimulation of angiogenesis.

HBO is administered in a chamber which is pressurized to the desired level and patients breathe $100 \%$ oxygen. Those with diabetic ulcers usually receive 20 to 60 treatments in total alongside conventional care. Transcutaneous oxygen pressure $\left(\mathrm{TcPO}_{2}\right)$ is a useful method for determining whether HBO is likely to be of benefit to the patient. This, along with thorough assessment and prescreening of patients, can ascertain the suitability for treatment and reduce the risk of side effects.

A number of clinical studies have been published demonstrating improved healing and a reduction in amputation rates for patients with diabetic ulcers. However, there is some inconsistency in the treatment regimens administered in some of the controlled trials. This paper provides an overview of the practicalities of treatment and the research supporting the use of HBO for diabetic lower extremity ulcers.
\end{abstract}

Keywords: HBO; Diabetic; Ulcer

\section{Introduction}

Hyperbaric oxygen (HBO) therapy is the intermittent inhalation of oxygen at pressures greater than the atmosphere. It was first used in the 1950s and 1960s. Boerema and colleagues [1] used HBO to assist with cardiopulmonary surgery and published 'Life without Blood' in 1960. Finding that it could inhibit anaerobic infections, Brummelkamp, et al. [2] successfully treated gas gangrene using HBO. Work was then completed on burns and in 1971, Rosenthal and Schurman reported improved healing in pressure ulcers. Work on HBO for diabetic ulcers has been relatively recent, from 1985 onwards.

The first International Congress on HBO was held in Holland in 1963 and the Undersea Medical Society, now known as the Undersea and Hyperbaric Medical Society (UHMS) was formed in 1967. The UHMS continue to regulate HBO in the United States today and there are societies across the world responsible for monitoring this treatment modality.

The conditions for which HBO is used are varied. However, diabetic lower extremity ulcers are one of those with a substantial number of research trials supporting its administration. It now forms part of the care package in many diabetic care facilities throughout the world for patients with diabetic lower extremity ulcers that are not responding to conventional treatment. The following pages will give an overview of HBO, including a brief overview of mechanisms of action and the practicalities of administration followed by a review of the research on diabetic ulcers and HBO.

\section{Mechanism of Action}

Normal wound healing progresses through four phases; haemostasis, inflammation, proliferation and remodelling. Wounds termed chronic or non-healing usually experience a prolonged inflammatory phase. Reasons for this include infection or lack of perfusion leads to abnormalities at a cellular level. Oxygen is essential throughout wound healing process. Initial injury leads to a hypoxic wound due to increased cell metabolism and damage to the tissue $[3,4]$. A tissue oxygen gradient develops between the hypoxic wound and the well-perfused periwound area and this gradient is believed to stimulate the diffusion of oxygen to the wound $[5,6]$. Oxygen is essential throughout wound healing, for processes such as antimicrobial activity, production of growth factors, angiogenesis and collagen synthesis $[7,8]$.

Breathing oxygen under hyperbaric conditions saturates the haemoglobin in the circulating blood and leads to increased levels of oxygen being dissolved into the plasma [9]. The oxygen in the plasma is more readily available than that bound to the haemoglobin. Therefore, in hyperbaric conditions, oxyhaemoglobin will pass unchanged from the arterial to 
the venous circulation [10]. In those patients with ischemic or vascular disease (such as in diabetics with ulcers) this effect has potential benefits including reduction of infection, encouragement of the transmigration of stem cells, stimulation of angiogenesis and minimizing necrosis.

It has also been demonstrated that HBO can reduce pathological inflammation by decreasing neutrophil adhesion and apoptosis $[11,12]$. This has the potential to facilitate healing in diabetic ulcers undergoing prolonged inflammation.

\section{Hyperbaric 0xygen Therapy}

HBO is administered in a chamber, which is pressurized to the desired level - usually 2.0 to 2.4 atmosphere absolute (ATA) for diabetic ulcers - and the patient breathes $100 \%$ oxygen for a total of 90 to 120 minutes either from the atmosphere or from a hood or mask as recommended by the Undersea and Hyperbaric Medical Society (UHMS) [13]. A typical treatment profile can be seen in Figure 1. Chambers are termed either multiplace, holding multiple patients simultaneously with or without an attendant, or monoplace, holding one patient (see Figure 2). Monoplace chambers are usually pressurized on $100 \%$ oxygen so having an advantage for patients who may find a hood or mask claustrophobic or for those who have tracheostomies or laryngectomies. In most centres where HBO is delivered, a member of staff enters the multiplace chamber with the patient(s). They are usually trained in basic life support and to provide interventions such as blood pressure measurement and blood glucose monitoring whichever be required.

Patients receive one treatment a day for 5 days a week with 2 off (usually the weekend) for a total number of 20 to 60 treatments depending upon the progress. Most centres will formally review progress after 20 to 30 treatments, and many conduct less formal daily or weekly wound assessments. The UHMS recommend review after 30 [13]. On occasions, it is deemed appropriate to treat patients twice daily, usually if the wound is severely infected or demarcation of the tissue is required quickly in more acute circumstances.

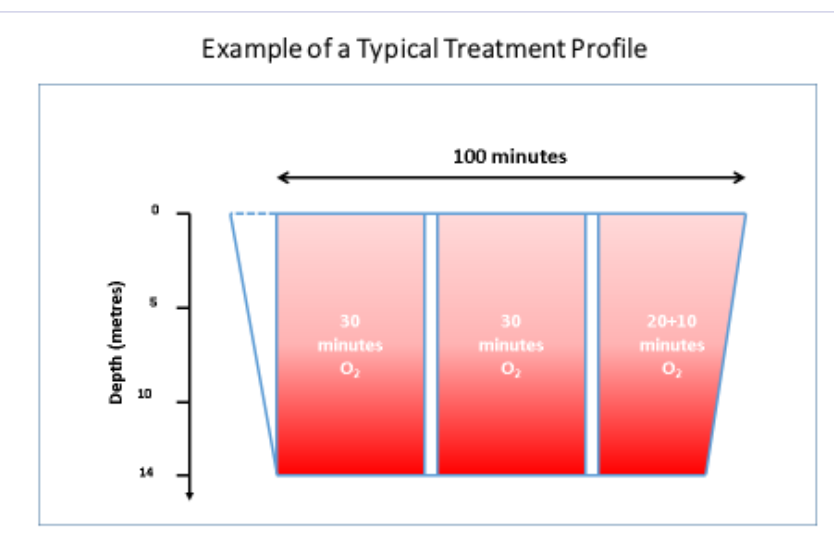

Figure 1: Example of a Typical Treatment Profile.
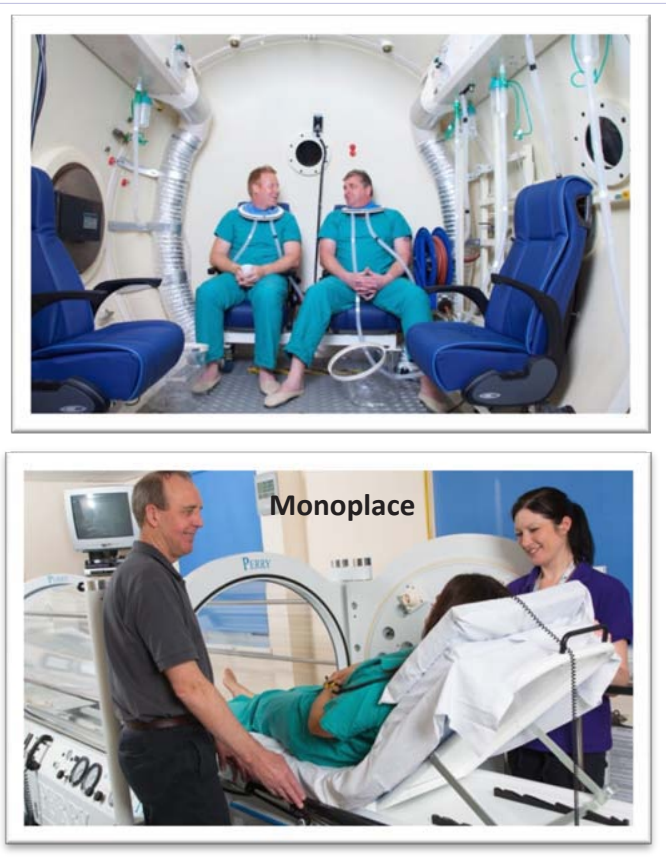

Figure 2: Multiplace and Monoplace Chambers.

\section{Patient Assessment}

\section{Side effects}

Although the side effects of HBO are relatively few, careful assessment and screening of patients prior to undergoing treatment can reduce the risk of their occurrence. Untreated pneumothorax and treatment with certain chemotherapy drugs are absolute contraindications while relative contraindications to HBO include chronic obstructive pulmonary disease, upper respiratory tract infections, history of thoracic or ear surgery, and pregnancy. The most common side effects of the increased oxygen are myopia, ear barotrauma and claustrophobia $[14,15]$. Rarer effects are central nervous system and pulmonary oxygen toxicity [15]. Some people experience a drop in blood sugar during treatment, which can be a problem for diabetic patients, therefore it is advised to eat prior to treatment and many clinicians recommend checking the blood sugar of diabetic patients immediately before HBO treatment with a blood glucose level check during therapy if the reading is the low end of normal.

\section{Transcutaneous oxygen monitoring}

Transcutaneous Oxygen Pressure $\left(\mathrm{TcPO}_{2}\right)$ uses a Clark electrode to measure oxygen. The electrode is heated (to $42-45^{\circ} \mathrm{C}$ ) to warm the skin causing capillary dilation, opening skin pores and decreasing oxygen solubility enabling tissue oxygen tension to be measured [16]. $\mathrm{TcPO}_{2}$ has been used in many vascular clinics since the early 1980s [16,17]. It is used in the hyperbaric centre to assess suitability and predict the outcome of HBO usually with one control probe used and at least one probe immediately adjacent to the wound to be treated. $\mathrm{TcPO}_{2}$ measurements are taken either at the surface with the patient breathing oxygen, or at the surface on air and compared with measurements in 
hyperbaric conditions with the patient breathing oxygen.

Fife, et al. [18] reported a thorough review on the outcomes of 1144 diabetic patients with ulcers at 6 hyperbaric centre's compared with their initial $\mathrm{TcPO}_{2}$ readings and observed that although breathing oxygen at sea level was $68 \%$ reliable for predicting success after HBO, it was unreliable for predicting failure. They found that measurement under hyperbaric conditions provides the best single discriminator between success and failure of treatment ( $74 \%$ reliable). A combination of surface-level air readings compared with $\mathrm{HBO}$ results predicts failure with $75.8 \%$ reliability (air reading of $<15 \mathrm{mmHg}$ combined with an $\mathrm{HBO}$ reading of $<400 \mathrm{mmHg}$ ).

\section{Wound dressings}

Dressings for patients undergoing HBO therapy are risk assessed for flammability. This is particularly important for treatments in a $100 \%$ oxygen filled monoplace chamber or for wounds that will be inside the hood or mask through which the patient is breathing oxygen. For example, wound dressings containing high levels of paraffin are unable to be used inside a chamber. Some centres collate information on the composition of a dressing or conduct internal testing to ensure safety; others prefer to stick to very basic dressings for HBO. This may mean daily dressing changes for the patient. Negative pressure wound therapy requires the pump to be disconnected for the duration of the treatment, as per manufacturers' instructions. Compression stockings are usually permitted, but an earthing strap is used to reduce any risk of static electricity.

Many centres have nurses specially trained in wound care to manage patients' wounds while they receive a course of treatment. This is usually done in collaboration with other members of the multidisciplinary team including professionals such as podiatrists. In addition to good wound care (including debridement as required) and multidisciplinary input, standard care for diabetic ulcers should include offloading, use of antibiotics and optimization of diabetic control and nutritional intake. HBO is an adjunctive therapy and all patients should continue to receive the standard treatment required during their course of treatment.

\section{Current Evidence for Diabetic Ulcers and HBO}

Lower extremity ulcers are a misfortune for a large number of diabetic patients. They frequently lead to amputation and subsequent increased mortality. A Scottish review reported that $65 \%$ of diabetics who had a major amputation died within 5 years [19] and a more recent German study by Hoffmann et al. [20] found that $44 \%$ and $19 \%$ of patients survived 5 and 10 years following amputation respectively. Therefore, healing ulcers initially and preventing amputation should be a priority.

There are a large number of published studies on HBO for diabetic lower extremity ulcers. A search of the literature reveals 12 prospective and 11 retrospective papers plus numerous case studies between 1987 and 2014. Unfortunately, controversy remains over the benefit of HBO for diabetic ulcers in many countries. The National Institute of Clinical Excellence [21] in the
United Kingdom (UK) advised that HBO was not a recommended treatment due to the lack of evidence supporting its use.

Some of this controversy is due to lack of consistency in the published research. Of the 12 prospective controlled trials, treatment regimen carried out varied from 2-3ata, 3 studies treated patients twice daily and a total number of treatments administered varied from 4 to 101 [22-33]. However, outcomes were more harmonious with 9 studies observing improved healing and 6 noting reduced amputation rates. Five papers reported the follow-up of between 6 months and 3 years. Kessler, et al. [29]; Margolis, et al. [33] did not observe a continued benefit from HBO at follow-up ( 6 weeks and 16 weeks after enrolment on the study respectively). Kessler, et al. [29] was the only study to treat patients twice daily throughout the administered patient: a regime not in line with guidelines issued by the UHMS Huang, et al. [13] who only recommends treating patients twice daily until any infection is resolved. Kessler, et al. [29] specified that none of the treated patients had infected ulcers. They gave no rationale for this unusual treatment regime.

The results of the longitudinal study by Margolis, et al. [33] differed significantly in its findings compared to the other studies. They reported outcomes for 6259 patients treated in 83 centres in the USA over a 5.5 year period. Patients received an average of 29 treatments. Unfortunately, there is some inconsistent reporting of the demographic data and lack of detail presented in the results. However, the overall conclusion was that results were unable to demonstrate that HBO improved healing or prevented amputation. In fact, they suggested that HBO patients were 1.5 to 3 times less likely to heal.

All but 2 of the trials compared HBO to a control group receiving conventional treatment alone. Abidia, et al. [28]; Löndahl, et al. [31] each compared patients receiving HBO to those undergoing a sham treatment. Abidia, et al. [28] randomized 8 patients to each group and gave treatment at 2.4 ATA, once daily for a total of 30 treatments. They observed improved healing at one year after treatment. Löndahl, et al. [31] randomized 49 patients to the HBO group and 45 to receive sham treatment. A maximum of 40 therapies were given at 2.5 ATA and improved healing was observed, with the largest difference in healing rate at 9 months after HBO. In order to avert non-healing, they assessed that the number needed to treat to avoid non-healing was 4.2 based on intention to treat analysis and 3.1 for, per protocol analysis.

The results of retrospective studies also demonstrate improved healing and reduced amputation rate, so supporting the adjunctive use of HBO for diabetic lower extremity ulcers. However, it is clear that for this therapy to become a more widely accepted treatment option further randomised controlled studies are required, especially considering the outcomes of Margolis, et al. [33].

Huang, et al. [13] reviewed the research in the development of their clinical practice guidelines on HBO for DFUs. Their recommendation for treatment regime has been specified above. However, they have recommended that future studies select a standardized regime including treatment pressure, length, 
frequency and duration in order to provide results that may provide more consistency.

\section{Conclusion}

HBO therapy is understood to reduce infection, promote transmigration of stem cells, reduce pathological inflammation, stimulate angiogenesis and minimize necrosis. While effective and timely specialist care is effective for most diabetic lower extremity ulcers, HBO can be of benefit to those patients with wounds where the normal wound healing process is interrupted or delayed. Thorough patient assessment and pre-treatment screening can reduce the risk of side effects experienced by the patients.

The evidence suggests that HBO may be a beneficial adjunct to treat patients with chronic diabetic lower extremity ulcers, although the lack of consistency in the published research has led to skepticism. $\mathrm{TcPO}_{2}$ measurements can assist in ensuring patients have more chance of benefiting from therapy and are not treated inappropriately. Further research would be of value along with better collation and sharing of outcomes for patients currently receiving HBO adjunctive to standard care, to establish the optimum treatment regime for best outcomes.

\section{References}

1. Boerema I, Meyne NG, Brummelkamp WK, Bouma S, Mensch MH, Kamermans F, et al. Life without blood: A study of the influence of high atmospheric pressure and hypothermia on dilution of the blood. J Cardiovasc Surg. 1959;13:133-146.

2. Brummelkamp WH, Boerema I, Hoogendyk L. Treatment of clostridial infections with hyperbaric oxygen drenching. A report on 26 cases. Lancet. 1963;1(7275):235-8.

3. Whitney JD. Physiologic effects of tissue oxygenation on wound healing. Heart Lung. 1989;18(5):466-74.

4. Tandara AA, Mustoe TA. Oxygen in wound healing: more than a nutrient. World J Surg. 2004;28(3):294-300.

5. Knighton DR, Silver IA, Hunt TK. Regulation of wound-healing angiogenesis - effect of oxygen gradients and inspired oxygen concentration. Surgery. 1981;90(2):262-270.

6. LaVan FB, Hunt TK. Oxygen and wound healing. Clin Plast Surg 1990;17(3):463-72.

7. Bishop AJ. Role of oxygen in wound healing. J Wound Care. 2008;17(9):399-402.

8. Eggleton P, Bishop AJ, Smerdon GR. Safety and efficacy of hyperbaric oxygen therapy in chronic wound management: current evidence. Chronic Wound Care Management \& Research. 2015;2:81-93.

9. Niinikoski JH. Clinical hyperbaric oxygen therapy, wound perfusion, and transcutaneous oximetry. World J Surg. 2004;28(3):307-11.

10. Jain KK. Textbook of hyperbaric medicine. 5th ed. Göttingen: Hogrefe; 2009.

11. Thom SR. Effects of hyperoxia on neutrophil adhesion. Undersea Hyperb Med. 2004;31(1):123-31.

12. Zhang Q, Chang Q, Cox RA, Gong X, Gould LJ. Hyperbaric oxygen attenuates apoptosis and decreases inflammation in an ischaemic wound model. J Invest Dermatol. 2008 Aug;128(8):2102-12. doi:

\subsection{8/jid.2008.53}

13. Huang ET, Mansouri J, Murad MH, Joseph WS, Strauss MB, Tettelbach W, et al. A clinical practice guideline for the use of hyperbaric oxygen therapy in the treatment of diabetic foot ulcers. Undersea Hyperb Med. 2015 May-Jun;42(3):205-47.

14. Dedi D, Prager T, Jacob R, Chan A, Fife CE. Visual acuity changes in patients undergoing hyperbaric oxygen therapy. Undersea Hyperb Med. 1998;25(34).

15. Gesell LB (Ed). Hyperbaric Oxygen 2003: Indications and Results: the Hyperbaric Oxygen Therapy Committee Report. Durham: UHMS. 2008.

16. Sheffield PJ. Measuring tissue oxygen tension: a review. Undersea Hyperb Med. 1998;25(3):179-88.

17. Dowd GS, Linge K, Bentley G. The effect of age and sex of normal volunteers upon the transcutaneous oxygen tension in the lower limb. Clin Phys Physiol Meas. 1983;4(1):65-8.

18. Fife CE, Buyukcakir C, Otto GH, Sheffield PJ, Warriner RA, Love TL, et al. The predictive value of transcutaneous oxygen tension measurement in diabetic lower extremity ulcers treated with hyperbaric oxygen therapy: a retrospective analysis of 1,144 patients. Wound Repair Regen. 2002;10(4):198-207.

19. Schofield CJ, Libby G, Brennan GM, MacAlpine RR, Morris AD, Leese GP. Mortality and hospitalization in patients after amputation: a comparison between patients with and without diabetes. Diabetes Care. 2006;29(10):2252-6.

20. Hoffmann M, Kujath P, Flemming A, Pro $\beta$ M, Begum N, Zimmermann $M$, et al. Survival of diabetes patients with major amputation is comparable to malignant disease. Diab Vasc Dis Res. 2015;12(4):26571. doi: $10.1177 / 1479164115579005$.

21. NICE . Type 2 diabetes foot problems: Prevention and management of foot problems. Manchester: NICE. 2008.

22. Baroni G, Porro T, Faglia E, Pizzi G, Mastropasqua A, Oriani G, et al. Hyperbaric oxygen in diabetic gangrene treatment. Diabetes Care. 1987;10(1):81-6.

23. Oriani G, Meazza D, Favales F, Pizzi GL, Aldeghi A, Faglia E. Hyperbaric oxygen therapy in diabetic gangrene. J Hyperb Med. 1990;5(3):171175 .

24. Doctor N, Pandya S, Supe A. Hyperbaric oxygen therapy in diabetic foot. J Postgrad Med. 1992;38(3):112-114.

25. Faglia E, Favales F, Aldeghi A, Calia P, Quarantiello A, Oriani G, et al. Adjunctive systemic hyperbaric oxygen therapy in treatment of severe prevalently ischemic diabetic foot ulcer. A randomized study. Diabetes Care. 1996 ;19(12):1338-43.

26.Zamboni WA, Wong HP, Stephenson LL, Pfeifer MA. Evaluation of hyperbaric oxygen for diabetic wounds: a prospective study. Undersea Hyperb Med. 1997;24(3):175-9.

27. Kalani M, Jorneskog G, Naderi N, Lind F, Brismar K. Hyperbaric oxygen (HBO) therapy in treatment of diabetic foot ulcers. Long-term followup. J Diabetes Complications. 2002;16(2):153-8.

28. Abidia A, Laden G, Kuhan G, Johnson BF, Wilkinson AR, Renwick PM, et al. The role of hyperbaric oxygen therapy in ischaemic diabetic lower extremity ulcers: a double-blind randomised-controlled trial. Eur J Vasc Endovasc Surg. 2003;25(6):513-8.

29. Kessler L, Bilbault P, Ortega F, Grasso C, Passemard R, Stephan D, et al. Hyperbaric oxygenation accelerates the healing rate of nonischemic 
chronic diabetic foot ulcers: a prospective randomized study. Diabetes Care. 2003;26(8):2378-82.

30. Duzgun, A.P., Satir, H.Z., Ozozan, O., Saylam, B., Kulah, B., \& Coskun, F. Effect of hyperbaric oxygen therapy on healing of diabetic foot ulcers. J Foot Ankle Surg. 2008;47(6):515-9. doi: 10.1053/j.jfas.2008.08.002.

31. Löndahl M, Katzman P, Nilsson A, Hammarlund C. Hyperbaric oxygen therapy facilitates healing of chronic foot ulcers in patients with diabetes. Diabetes Care. 2010;33(5):998-1003. doi: 10.2337/dc091754
32. Ma L, Li P, Shi Z, Hou T, Chen X, Du J. A prospective, randomized, controlled study of hyperbaric oxygen therapy: effects on healing and oxidative stress of ulcer tissue in patients with a diabetic foot ulcer. Ostomy Wound Manage. 2013;59(3):18-24.

33. Margolis DJ, Gupta J, Hoffstad O, Papdopoulos M, Glick HA, Thom SR, Mitra N. Lack of effectiveness of hyperbaric oxygen therapy for the treatment of diabetic foot ulcer and the prevention of amputation : a cohort study. Diabetes Care. 2013;36(7):1961-6. doi: 10.2337/dc122160 . 